\title{
Gene silencing in Caenorhabditis elegans by transitive RNA interference
}

\author{
MATTHEW N. ALDER, SHALE DAMES, JEFFREY GAUDET, and SUSAN E. MANGO
}

Huntsman Cancer Institute, University of Utah, Salt Lake City, Utah 84112, USA

\begin{abstract}
When a cell is exposed to double-stranded RNA (dsRNA), mRNA from the homologous gene is selectively degraded by a process called RNA interference (RNAi). Here, we provide evidence that dsRNA is amplified in Caenorhabditis elegans to ensure a robust RNAi response. Our data suggest a model in which mRNA targeted by RNAi functions as a template for $5^{\prime}$ to $3^{\prime}$ synthesis of new dsRNA (termed transitive RNAi). Strikingly, the effect is nonautonomous: dsRNA targeted to a gene expressed in one cell type can lead to transitive RNAi-mediated silencing of a second gene expressed in a distinct cell type. These data suggest dsRNA synthesized in vivo can mediate systemic RNAi.
\end{abstract}

Keywords: RNA interference; transitive RNAi; C. elegans; pha-4; RdRP

\section{INTRODUCTION}

Introduction of dsRNA into cells induces degradation of homologous mRNA by a process called RNA interference (RNAi) in animals or post-transcriptional gene silencing (PTGS) in plants (Bernstein et al. 2001b; Mango 2001; Sharp 2001; Zamore 2001). A two-step mechanism has been proposed for dsRNA-mediated degradation based on genetic and biochemical studies. In the first stage, dsRNA, bound by cellular factors such as Dicer/DCR-1 (Bernstein et al. 2001a; Grishok et al. 2001; Ketting et al. 2001; Knight and Bass 2001), is processed into 21-23 nucleotide pieces called siRNAs. In the second stage, siRNAs guide the degradation machinery to target mRNA, which is cleaved endonucleolytically (Zamore et al. 2000; Elbashir et al. 2001a). The machinery responsible for degradation is called RISC and includes Argonaute2 in Drosophila (Bernstein et al. 2001a; Hammond et al. 2001). A similar complex probably exists in other organisms (Catalanotto et al. 2002; Hutvagner and Zamore 2002; Mourelatos et al. 2002; Tabara et al. 2002). Additional genes required for RNAi have been identified, although their precise functions are unclear. These include genes homologous to RNA helicases (Domeier et al. 2000; Wu-Scharf et al. 2000; Dalmay et al. 2001; Tijsterman

Reprint requests to: Susan Mango, Huntsman Cancer Institue, University of Utah, 2000 Circle of Hope, Salt Lake City, UT 84112, USA; e-mail: susan.mango@hci.utah.edu.

Article and publication are at http://www.rnajournal.org/cgi/doi/ 10.1261/rna.2650903. et al. 2002), DNA helicases (Cogoni and Macino 1999b; Ketting et al. 1999), RNA-directed RNA polymerases (Cogoni and Macino 1999a; Mourrain et al. 2000; Smardon et al. 2000), double-stranded RNA-binding proteins (Tabara et al. 2002), as well as additional Argonaute members (Tabara et al. 1999; Fagard et al. 2000). In several organisms, Argonaute homologs are not required to produce siRNAs, suggesting this family may function downstream of dsRNA processing (Parrish and Fire 2001; Catalanotto et al. 2002; Tijsterman et al. 2002). The loss-of-function phenotypes associated with some of these loci suggest that RNAirelated mechanisms are important for multicellular development and protection from transposons and viruses (Sharp 2001; Zamore 2001).

Previous experiments revealed that even small amounts of dsRNA are effective for silencing, suggesting the RNAi signal may be amplified. For example, an estimated $\sim 2$ dsRNA molecules per cell are sufficient to inactivate abundant unc-22 RNAs (Fire et al. 1998). One explanation for this effect is that the initial RNAi signal is replicated to produce new dsRNA (discussed in Mango 2001). Recently, Fire and colleagues provided evidence that dsRNA is amplified in Caenorhabditis elegans (Sijen et al. 2001). Similarly, Paterson and colleagues observed de novo synthesis of dsRNA in Drosophila extracts using either dsRNA or target mRNA as template (Lipardi et al. 2001). However, questions concerning replication of dsRNA remain because other Drosophila studies failed to detect evidence of de novo synthesis in vitro (Zamore et al. 2000; Elbashir et al. 2001a; 
Hutvagner and Zamore 2002) or in vivo (Celotto and Graveley 2002). Similarly, Parrish et al. (2000) showed that exogenous dsRNA is not a template for replication in vivo in C. elegans, at least to any significant degree. Finally, the Drosophila genome lacks obvious candidate genes to mediate RNA-directed RNA synthesis. These conflicting observations raised the question of whether dsRNA is synthesized in vivo and, if so, the nature of the template. Our findings suggest that dsRNA is amplified in vivo in C. elegans, in agreement with Sijen et al. (2001). We also provide genetic evidence that amplified dsRNA can move between cells.

\section{RESULTS AND DISCUSSION}

To determine whether target mRNA is a likely template for dsRNA synthesis in vivo, we designed an assay to detect spreading of the RNAi signal with respect to mRNA target sequences ("transitive RNAi"; Fig. 1A). We generated transgenic worm carrying a translational fusion of green fluorescent protein (GFP) inserted into the pha-4 gene (Labouesse and Mango 1999; see Materials and Methods). We initiated RNAi with this strain by microinjecting fulllength GFP dsRNA (GFP-FL, the trigger dsRNA). If pha-4::GFP target mRNA is used as a template to synthesize new dsRNA, some of this dsRNA should be homologous to pha-4 and able to silence both the chimeric mRNA and endogenous pha-4. Silencing of endogenous pha-4 is predicted to kill progeny worms because pha-4 is essential (Mango et al. 1994), whereas silencing of the pha-4::GFP chimera alone should not affect viability.

Our data demonstrate that transitive RNAi can lead to silencing of new mRNA targets, presumably by de novo synthesis of dsRNA. GFP dsRNA introduced into pha-4::GFP transgenic worms resulted in striking lethality in which $>80 \%$ of the progeny of most injected worms died (Fig. 1B). These worms arrested at the first larval stage, similar to animals with reduced but not null pha-4 activity

A

B

C

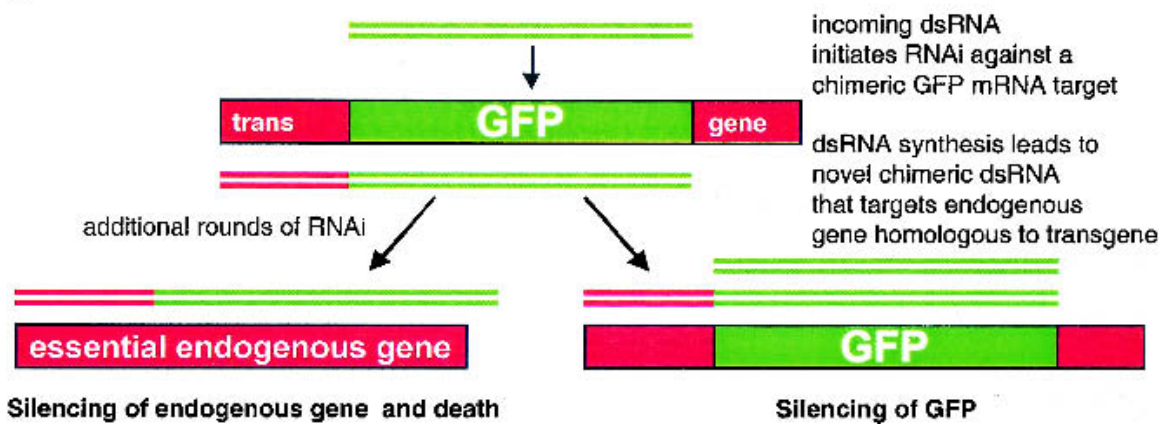

\begin{tabular}{|c|c|c|c|c|}
\hline Worm & & & $\mathbf{R N}$ & -induced \\
\hline Recipient & Transgene & dsRNA & Leth & ality? \\
\hline WT & - & $\overline{\text { GFP-FL }}$ & no & $(n=0 / 8)$ \\
\hline pha-4::GFP & GEP & GFP-FL & yes & 19/23) \\
\hline$t \mid f-1:: G F P$ & GFP & GFP-FL & yes & $(n=15 / 17)$ \\
\hline$p G F P$ & GFP & GFP-FL & no & $(n=0 / 31)$ \\
\hline WT & - & $60 \mathrm{~B}$ & yes & $(n=48 / 49)$ \\
\hline WT & - & un & yes & $(n=10 / 10)$ \\
\hline unc-60(su158) & - & unc- $60 \mathrm{~B}$ & no & $(n=0 / 29)$ \\
\hline
\end{tabular}

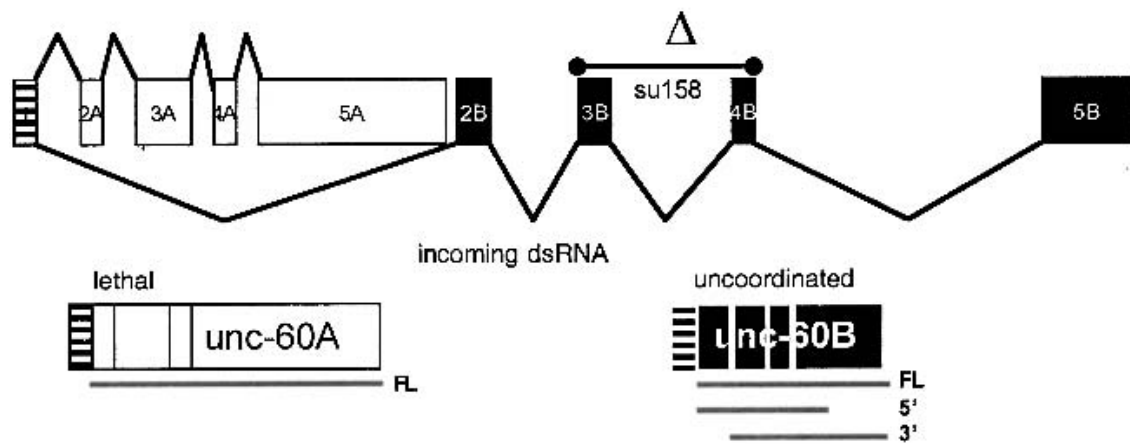

FIGURE 1. Genetic evidence for dsRNA amplification in vivo. (A) If target mRNA functions as a template for synthesis of new dsRNA, then dsRNA directed against a translational fusion between GFP (green) and a C. elegans gene (red) will lead to the production of new dsRNA that can target the endogenous C. elegans gene (red lines). This phenomenon is called transitive RNAi. Here and throughout, target mRNAs are depicted as boxes and dsRNA as lines. (B) Injection of full-length GFP dsRNA (GFP-FL) leads to killing of $p h a-4:: G F P$ and tlf-1::GFP worms but not $p G F P$ or wild-type animals (top four rows). Injection of full-length unc-60B dsRNA kills wild-type worms but not unc-60B mutants (bottom two rows). $\left(n^{\prime}\right)$ The number of mothers whose progeny were scored except for unc- $60 \mathrm{~B}$ where mothers were typically scored. A total of $83 \%$ of wild-type animals injected with unc- $60 \mathrm{~B}$ dsRNA died and, for the surviving mothers, none of their progeny survived. (C) unc-60 produces two mRNAs, A and B, which share a common first exon (hatched box). RNAi is initiated using $u n c-60 B$ dsRNA and progeny animals scored for lethal $(u n c-60 A+B)$ or uncoordinated (unc-60B) phenotypes. (FL) Full-length 453-bp dsRNA for either unc-60A or unc-60B. (5') 358-bp dsRNA located 2 nucleotides from the exon $1 / 2$ boundary. (3') 360-bp dsRNA located 96 nucleotides from the exon $1 / 2$ boundary.
(Gaudet and Mango 2002). Lethality depended on pha-4 exonic sequences as GFP dsRNA injected into either wildtype worms or worms expressing a transcriptional fusion between pha-4 and GFP had no effect ( $p G F P$; Fig. 1B). Importantly, GFP dsRNA injected into $p G F P$ transgenic 
animals abolished GFP expression, indicating that RNAimediated silencing had occurred (data not shown; Fig. 5B, below).

We tested two additional genes to demonstrate the generality of transitive RNAi. The first was a translational fusion between the essential gene tlf-1 (Kaltenbach et al. 2000) and GFP. GFP dsRNA was used to target the tlf-1::GFP fusion by microinjection and consequently endogenous tlf-1 (Fig. 1B). These embryos arrested with Tlf-1 phenotype (Fig. 2). The second gene examined was the endogenous unc-60 locus (Fig. 1B,C). Normally, unc-60 produces two mRNAs, $\mathrm{A}$ and $\mathrm{B}$, which share a common first exon but are otherwise different (McKim et al. 1994). Mutations in unc$60 \mathrm{~A}$ and $u n c-60 \mathrm{~B}$ are associated with different phenotypes, lethal and uncoordinated, respectively, enabling us to determine which mRNAs were degraded during RNAi. Introduction of dsRNA specific for unc-60B by microinjection resulted in a lethal phenotype for either injected mothers or $>50 \%$ of their progeny (Fig. 1B). This result suggests that unc- $60 \mathrm{~B}$ dsRNA targeted both unc- $60 \mathrm{~A}$ and unc- $60 \mathrm{~B}$ transcripts.

We performed two controls to demonstrate that lethality induced by $u n c-60 B$ dsRNA was specific. First, we used a dsRNA positioned $96 \mathrm{bp}$ from the exon 1-2 boundary to induce silencing (Fig. 1C, 3' construct). Because transitive RNAi can travel only short distances (see below), we predicted this dsRNA would inactivate $u n c-60 B$ but not unc$60 \mathrm{~A}$. As expected, we observed Unc animals but no lethality when this dsRNA was used to induce silencing by microinjection (7/10 Unc, 0/10 Let). A dsRNA of a similar size but located 2 base pairs from the exon 1-2 boundary was
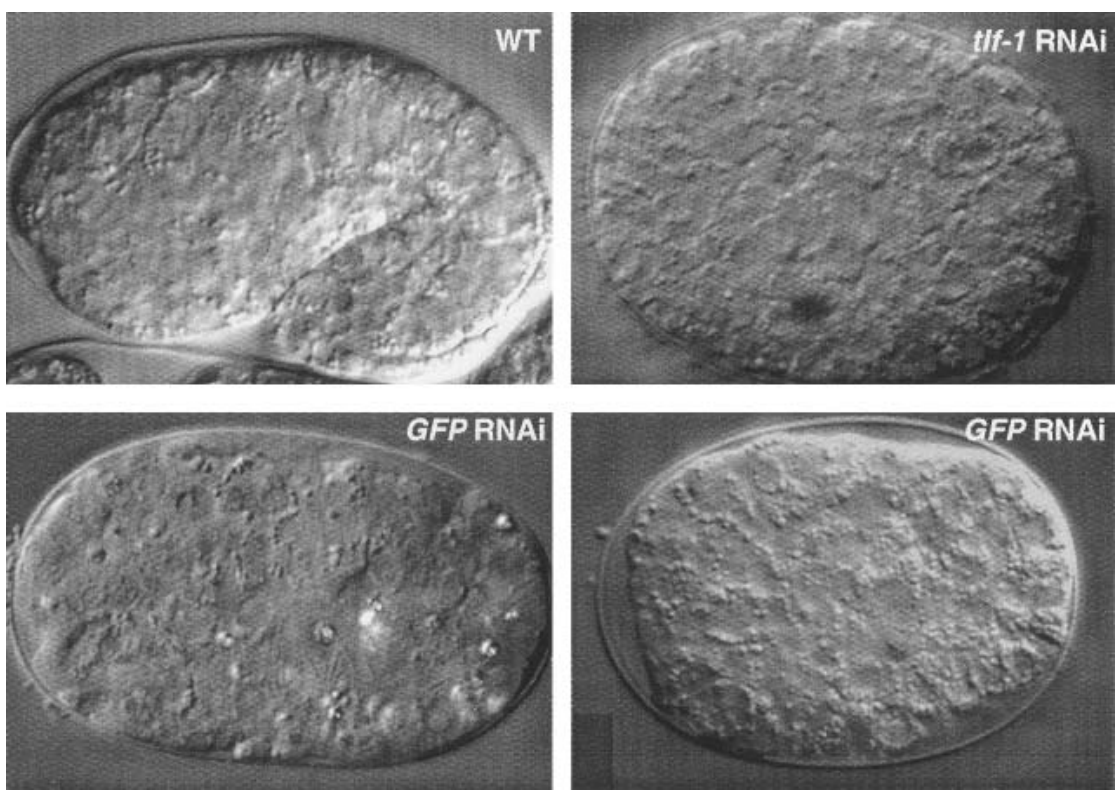

FIGURE 2. Phenotype of $t l f-1:: G F P$ transgenic animals treated with GFP dsRNA. (Top) Wildtype worms treated with no dsRNA (WT) or tlf-1 dsRNA (tlf-1 RNAi). (Bottom) Two examples of arrested embryos from tlf-1::GFP transgenic worms treated with GFP dsRNA (GFP RNAi). able to induce lethality similar to full-length dsRNA indicating that location of the dsRNA, not its size, was important for killing (0/8 Unc, 7/8 Let; Fig. 1C, 5' construct). Second, the allele unc-60(su158) carries a deletion within unc- $60 \mathrm{~B}$ that is predicted to destabilize the mature $u n c-60 \mathrm{~B}$ mRNA while leaving unc-60A intact (Fig. 1C; Mango 2001; S. Ono, pers. comm.). We reasoned that if transitive RNAi depends on mature unc-60B sequences, this allele should suppress the lethality associated with unc-60B-mediated RNAi because mature unc-60B(su158) mRNA could not function as a template. We injected unc-60B dsRNA into unc-60(su158) homozygotes and found, as expected, that all mothers and offspring survived (Fig. 1B). Our data suggest unc-60A mRNA is a target for transitive RNAi from unc-60B sequences.

One intriguing possibility is that antisense RNAs from the trigger dsRNA function as primers during transitive RNAi. If so, the process should be directional. Synthesis of an antisense strand of RNA from $5^{\prime}$ to $3^{\prime}$ using the $3^{\prime}$ hydroxyl of the antisense RNA primer (Elbashir et al. 2001a) is predicted to produce dsRNA complementary to mRNA sequences $5^{\prime}$ of the domain targeted by the trigger dsRNA, but not $3^{\prime}$. Three lines of evidence support this model. First, we showed directionality for the mRNA target. We constructed a transgene carrying pha-4 sequences $3^{\prime}$ of GFP (GPtxg) and initiated RNAi with GFP-FL dsRNA (Fig. 3). Whereas GFP-FL dsRNA could silence GFP expression as effectively for this transgene as for pha-4::GFP, we observed no transitive RNAi-induced killing (Fig. 3). These findings indicate that transitive RNAi targets mRNA sequences located $5^{\prime}$ of the mRNA sequences homologous to incoming dsRNA.

As a second approach, we tested directionality of exogenously introduced dsRNA. We used different fragments of GFP dsRNA to initiate RNAi by microinjection (Fig. 3). GFP-5' and GFP-3' are dsRNAs homologous to the $5^{\prime}$ and 3 ' halves of full-length GFP, respectively. GFP-mid is an equivalently sized dsRNA from the middle of GFP. We reasoned that all three GFP dsRNAs should be competent to interfere with expression of GFP transgenes. However, GFP dsRNA homologous to sequences close to the appropriate pha-4-GFP junction of the target mRNA should be more effective for transitive RNAi-mediated killing than GFP dsRNA homologous to sequences far from the junction. This prediction rests on the idea that killing requires synthesis of new dsRNAs that extend from the priming antisense RNA to sequences homologous to pha-4 and that spreading is likely to be sensitive to distance. GFP-5' and GFP-3' 


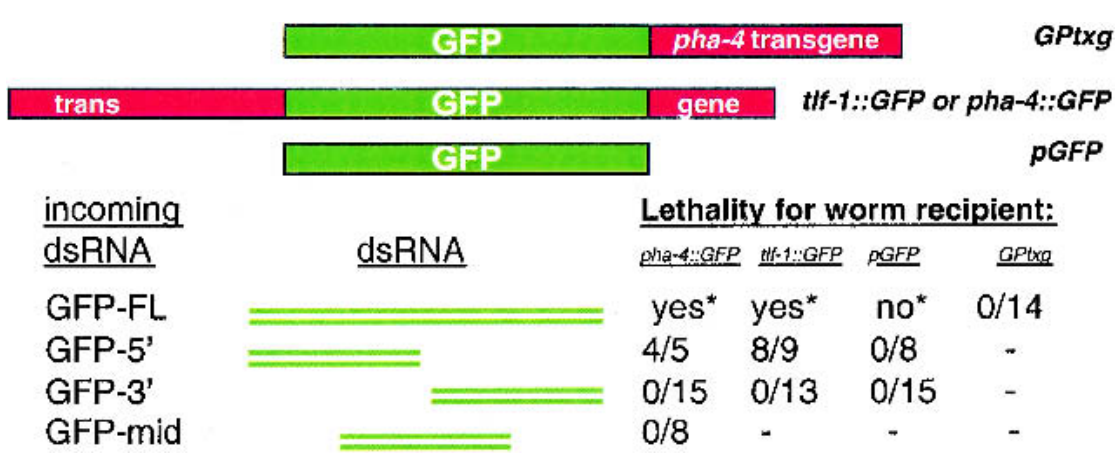

FIGURE 3. Transitive RNAi moves $5^{\prime}$ to $3^{\prime}$. dsRNA homologous to full-length, $5^{\prime}, 3^{\prime}$, or middle of GFP was used to initiate RNAi in worms carrying one of five transgenes: $P G$ txg, GPtxg, pha-4::GFP, tlf-1::GFP, or pGFP. $\left(^{*}\right)$ Effects of GFP-FL for pha-4::GFP, tlf-1::GFP, and $p G F P$ worms are from Figure 1.

dsRNA each flank a pha-4-GFP junction, but at different positions. The junction is $5^{\prime}$ relative to the mRNA sequences homologous to trigger dsRNA for GFP-5' and $3^{\prime}$ for GFP-3' (Fig. 3). We found that GFP-5' dsRNA was as competent to induce a lethal phenotype as GFP-FL for both pha-4::GFP and tlf-1::GFP transgenes. This result suggests that dsRNA synthesis targets mRNA sequences located $5^{\prime}$ of those homologous to the exogenous dsRNA. By contrast, neither GFP-3' nor GFP-mid dsRNA induced killing even though they were as effective for silencing GFP as GFP-5'. These experiments suggest that dsRNA is synthesized from $5^{\prime}$ to $3^{\prime}$ and is sensitive to distance.

Our third line of evidence for directionality of transitive RNAi is based on the unc-60A/B experiment described above. The only sequences shared between these mRNAs are those of the common first exon, suggesting that synthesis of dsRNA is $5^{\prime}-3^{\prime}$ (Fig. 1C). Together, these experiments demonstrate that transitive RNAi-induced killing involves mRNA sequences located $5^{\prime}$ of those homologous to the trigger dsRNA. We conclude that transitive RNAi moves from the initiating siRNA (or other antisense RNA) toward the $5^{\prime}$ end of the mRNA (i.e., $5^{\prime}-3^{\prime}$ synthesis), which agrees with the findings of Sijen et al. (2001) and Lipardi et al. (2001). What determines directionality? One possibility is that the siRNA functions as a primer to initiate elongation. Previous analyses are consistent with a primer function during RNAi in C. elegans (Tijsterman et al. 2002). Alternatively, directionality may reflect differential stability of potential templates for RNA synthesis derived from a cleaved target mRNA. The $5^{\prime}$ fragment may be more stable than the $3^{\prime}$ fragment and therefore used more frequently as a template. Finally, the machinery required for RNA synthesis may be associated with RISC and positioned by this complex for unidirectional RNA synthesis.

We observe only short-range effects, fewer than 100 or 180 bases. Neither GFP-3' nor GFP-mid dsRNA induced lethality even though these dsRNAs were only 358 bases and 180 bases, respectively, from the $5^{\prime}$ pha-4-GFP junction. Similarly, the unc- $60 B 3^{\prime}$ construct was only 96 bases from the exon 1-2 boundary and yet failed to induce transitive RNAi. This result is similar to Sijen et al. (2001), but different from Lipardi et al. (2001), who observed synthesis of full-length RNAs.

We next examined transitive RNAi from the perspective of the trigger dsRNA. We used a dsRNA hairpin that carried GFP sequences in the stem and unc-22 sequences in the loop (Fig 4A; Winston et al. 2002). We predicted these molecules would be processed into siRNAs starting from the free end of the stem and ending with the last fragment of dsRNA carrying the unc-22 loop at one end. This prediction stems from in vitro data that revealed single-stranded RNA can block dsRNA processing in Drosophila (Elbashir et al. 2001a). We asked whether we could observe Unc-22 mutant phenotypes as a consequence of unc-22 dsRNA synthesized de novo.

Unc-22 animals were generated when GFP-unc-22 hairpin dsRNA produced in bacteria was fed to animals carrying pha-4::GFP, pGFP, or tlf-1::GFP transgenes (Figs. $4 \mathrm{~B}$ and $5 A)$. The severity of the Unc-22 phenotype differed between the three strains, suggesting that the Unc-22 phenotype depended on the abundance or cellular expression of the mRNA target (Fig. 4B; data not shown). The pha-4::GFP transgenic strain had the strongest phenotype, with $100 \%$ living worms becoming severely uncoordinated. tlf-1::GFP gave the weakest phenotype, with only mild effects on movement. By contrast, GFP-unc-22 hairpin dsRNA never induced an Unc-22 phenotype in wild-type animals that lacked a GFP transgene, indicating that an mRNA target was essential (Figs. 4B and 5A). To ensure that all three strains were susceptible to unc-22 RNAi, we also performed a titration of unc-22 dsRNA alone. We observed some variability in responsiveness to unc-22 dsRNA, but it was not sufficient to explain the dramatic differences in Unc-22 phenotypes induced by the hairpin dsRNA. For example, in some experiments pha-4::GFP behaved identically to wildtype worms, whereas in others we saw a mild enhancement of RNAi (data not shown). We suggest that unc-22 dsRNA is produced via transitive RNAi from hairpin constructs. One speculative but exciting model is that cleaved mRNA can function as a primer for dsRNA synthesis (Fig. 4A, left). Alternatively, siRNAs homologous to GFP may function as primers with a hairpin dsRNA template (Fig. 4A, right). In the latter scenario, the role of the GFP transgene might be to produce large numbers of siRNAs or structurally modified siRNAs that could function as primers.

The difference in phenotypes with various mRNA targets and GFP-unc-22 hairpin dsRNA provides a possible explanation why transitive RNAi using dsRNA hairpins was not detected previously (Parrish et al. 2000). The mRNA targets used in the previous study may not have been as effective as 
A

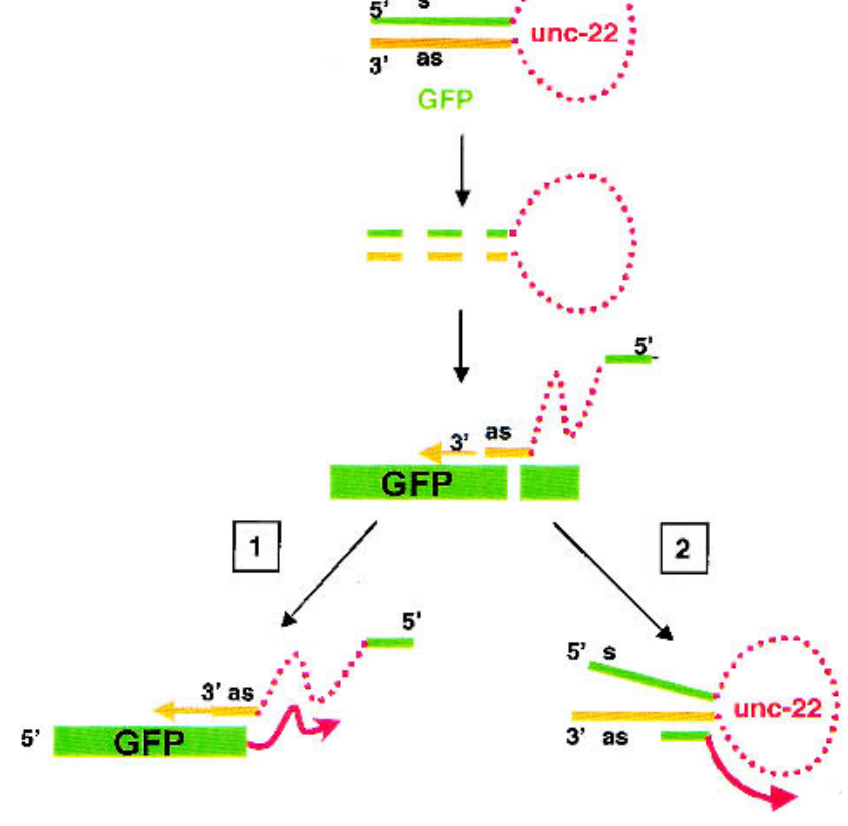

B

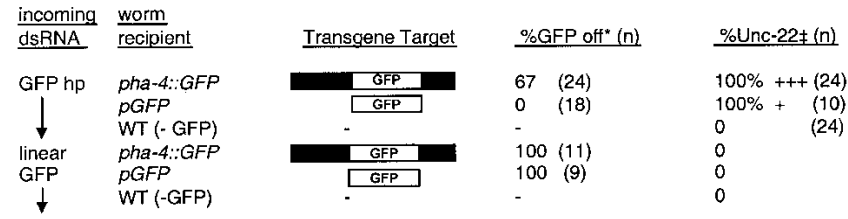

FIGURE 4. Two models for RNAi with loop sequences of a dsRNA hairpin. (A) GFPhp is a dsRNA hairpin with GFP sense RNA(s) on the $5^{\prime}$ end of the stem and GFP antisense RNA (as) on the $3^{\prime}$ end of the stem; unc-22 sequences are located in the loop (Winston et al. 2002). The hairpin is predicted to undergo processing to form siRNAs, with the last fragment of dsRNA bearing the unc-22 loop. Association of siRNAs with the GFP mRNA will induce endonucleolytic cleavage of the target. Cleaved GFP mRNA may function as a primer to synthesize a complementary strand of unc-22 RNA using the loop-containing siRNA as template $(1$, left $)$. Alternatively, siRNAs generated during GFP RNAi may prime dsRNA synthesis with a new GFPhp (2, right). (B) Silencing of GFP and unc-22. $\left(^{*}\right)$ Percentage of animals with GFP completely off. ( $\ddagger)$ Percentage of uncoordinated animals. (+++) Animals that were paralyzed on the plate; $(+)$ animals that were sluggish or egg-laying defective. $p G F P$ is not silenced effectively by GFPhp feeding, but presumably some RNAi is occuring since this strain was tested concurrently with pha-4::GFP.

pha-4::GFP. Moreover, we observed Unc-22 phenotypes when hairpin dsRNA was administered continuously but not when a single dose of dsRNA was applied by microinjection (see Materials and Methods). Parrish et al. (2000) relied on microinjection in their studies. One possibility is that a stable supply of hairpin dsRNA is important for a sustained reduction of $u n c-22$ mRNA and generation of an Unc-22 phenotype.

The GFP-unc-22 hairpin experiment revealed that a molecule produced during transitive RNAi, presumably dsRNA, can move between cells. Previous work showed that RNAi can spread from cell to cell (for review, see Sharp 2001; see also Winston 2002). The systemic nature of RNAi is functional in rde-4 mutants even though these animals cannot produce siRNAs efficiently (Grishok et al. 2000; Parrish and Fire 2001). These data suggest that siRNAs are not required for systemic RNAi but leave open the nature of the dsRNA molecule involved. One possibility is that a larger dsRNA could be involved. Tabara et al. (2002) detected a larger 100-bp RNA associated with RDE-4 in worms undergoing RNAi and Boutla et al. (2002) have implicated an 85-bp species from plants that can induce RNAi in worms. These RNAs could represent cleaved trigger dsRNA or replicated dsRNA. In our experiments, we observed transitive RNAi when the primary mRNA target was expressed in one cell type and the secondary mRNA target in another. GFP-unc22 hairpin dsRNA introduced into pha-4::GFP or $p G F P$ transgenic strains produced a strong Unc-22 phenotype even though expression of these transgenes was restricted to the digestive tract whereas $u n c-22$ is limited to body wall muscles (Fig. 5B; Moerman and Fire 1997). Conversely, tlf-1::GFP transgenic worms gave the weakest Unc-22 phenotype in side by side comparisons (Fig. 4B) even though tlf-1::GFP is expressed ubiquitously, including body wall muscles (Kaltenbach et al. 2000; data not shown). Although we cannot rule out that some small amount of pha-4::GFP is expressed in body wall muscles, we clearly do not observe a concordance between the level of GFP in body wall muscles and the Unc-22 phenotype. We propose this effect may reflect the level of GFP in individual cells, especially those of the digestive tract that presumably receive most of the ingested dsRNA. Because transitive RNAi depends critically on a transgene, our data also suggest that a product of transitive RNAi, presumably dsRNA, can move between cells. This product may not be siRNA, based on the $r d e-4$ data described above.

What molecules mediate transitive RNAi? One attractive candidate is RNA-directed RNA polymerase (RdRP), which is required for RNAi in worms (Smardon et al. 2000; Sijen et al. 2001), Neurospora (Cogoni and Macino 1999a), Arabidopsis (Dalmay et al. 2000; Fagard et al. 2000; Mourrain et al. 2000), and Dictyostelium (Martens et al. 2002). RdRPs have been studied in tomato, where they synthesize an RNA complement from a single-stranded RNA or DNA template in vitro (Schiebel et al. 1993a,b, 1998). In plants and Dictyostelium, the amount of siRNA decreases when RdRP is inactivated, consistent with the existence of a replicative dsRNA amplification step (Dalmay et al. 2000; Martens et al. 2002). However, because RdRPs are required for all RNAi, it is not possible to determine whether they play a specific role in transitive RNAi. The loss of RNAi in RdRP mutants could reflect the absolute requirement for an amplification step to produce enough siRNAs to reach a critical threshold for silencing. Alternatively, RdRPs could perform some other function that remains to be discovered. Con- 
A
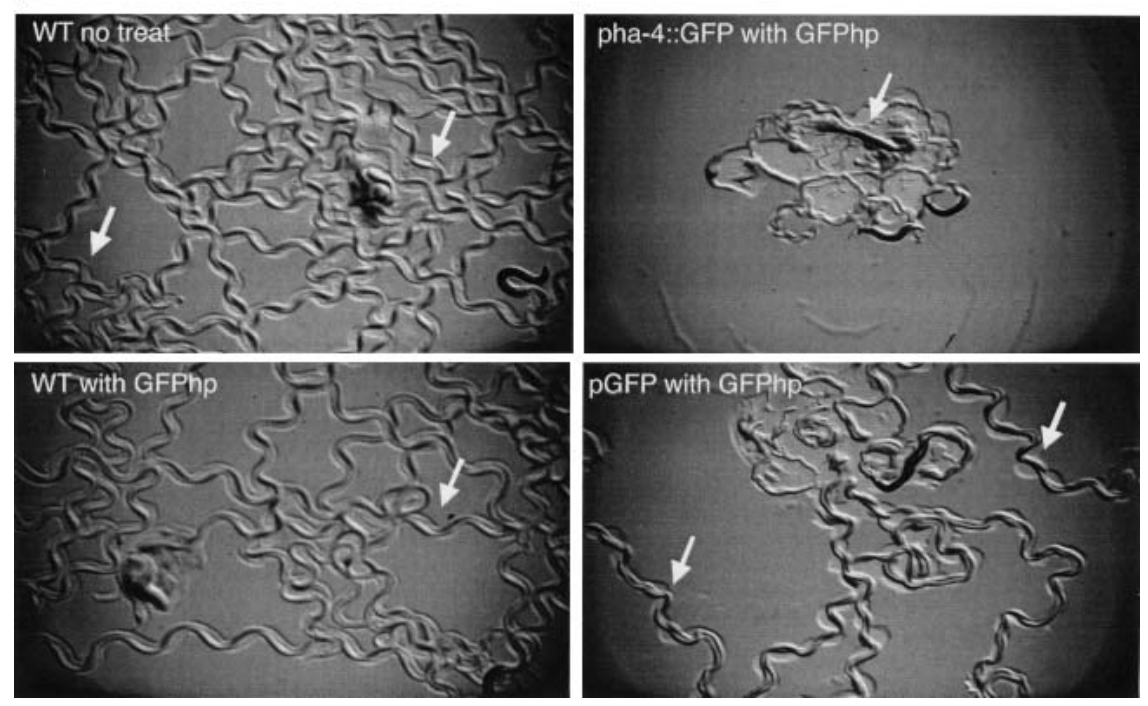

B
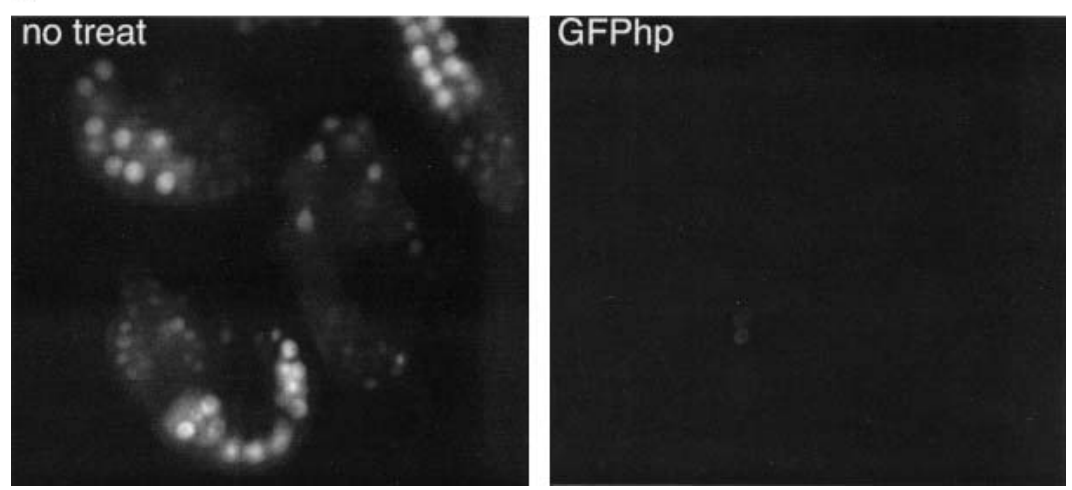

FIGURE 5. Phenotypes of worms exposed to dsRNA hairpins. (A) Motility of wild-type (WT), pha-4::GFP, or $p G F P$ transgenic worms after RNAi induced with GFP- unc-22 hairpin dsRNA (GFPhp). Three F1 animals were allowed to move freely for $11 \mathrm{~min}$ and photographed in the absence (no treat) or presence of GFP-unc-22 hairpin dsRNA. (B) GFP fluorescence for pha-4::GFP transgenic worms treated with no dsRNA (no treat), or GFP-unc-22 hairpin dsRNA (GFPhp).

sistent with this idea, loss of $S D E 1 / R d R P$ activity in Arabidopsis blocks mRNA degradation even though siRNAs accumulate (Vaistij et al. 2002). In C. elegans, a biochemical activity for RdRP homologs has not yet been documented.

Interestingly, Drosophila and mammals do not carry an RdRP homolog, suggesting transitive RNAi may not occur in these organims. Several studies are consistent with this idea, both in vivo (Celotto and Graveley 2002; Holen et al. 2002) and in vitro (Zamore et al. 2000; Elbashir et al. 2001b; Nykanen et al. 2001; Hutvagner and Zamore 2002). However, other studies have suggested amplification can occur in Drosophila (Lipardi et al. 2001). The discrepancy between the different studies may reflect differences in the balance between dsRNA synthesis versus mRNA degradation activities in vitro versus in vivo. Alternatively, perhaps some cells carry viruses that produce RdRP enzymes, providing a pos- sible source for the potent replication activity seen in some studies but not others.

In closing, we note that the GFP-unc22 hairpin used in these studies may have a natural counterpart in vivo. RNAi suppresses transposition of $\mathrm{Tcl} /$ mariner type transposons, which carry inverted repeats at each end (Plasterk and van Luenen 1997; Sharp 2001; Zamore 2001). The configuration of transposon RNA is unknown, but at least some transcripts may be read-through products initiated at adjacent cellular promoters. If so, these RNAs would form hairpins. The GFPhp hairpin used in this study resembles the likely structure of hairpin transposon RNA, with the inverted repeats forming the stem and the body of the transposon in the loop (Plasterk and van Luenen 1997). The small size of the inverted repeat within some transposons suggests that few siRNAs would be made during initial RNAi and therefore transposon RNAs would be poor RNAi targets. Transitive RNAi provides the cell with an elegant solution to this problem. Synthesis of new dsRNA complementary to the transposon loop, analogous to the unc-22 loop of GFPhp, would enable the cell to silence transposon RNAs more effectively.

\section{MATERIALS AND METHODS}

\section{Worm growth}

Strains were maintained at room temperature $\left(22^{\circ}-23^{\circ}\right)$ following Brenner (1974). For all but the hairpin constructs, dsRNA was synthesized and microinjected as described in Kaltenbach et al. (2000). Adults were injected except for the unc-60B experiments ( 360 and 358 bp dsRNA) where we obtained stronger phenotypes when we injected fourth-stage larvae. Progeny laid 40-48 h post-injection were scored for GFP fluorescence and lethality over the following two days. For the hairpin constructs, RNAi was initiated by bacterial feeding (Timmons and Fire 1998; Timmons et al. 2001). First- and second-stage larvae were placed on plates seeded with RNase III-deficient bacteria expressing dsRNA and induced with $1 \mathrm{mM}$ IPTG (Timmons et al. 2001). Worms were transferred daily to freshly seeded plates. Progeny laid $48 \mathrm{~h}$ after Po larvae had been placed on the plates were scored for GFP fluorescence. Unc-22 phenotypes were scored mostly in Po animals after $48 \mathrm{~h}$ although progeny were also Unc whereas wild-type animals were not. Four independent experiments were performed for the dsRNA hairpin experiments. The structures of the hairpin construct was confirmed by restriction enzyme digest before and after each experiment. 


\section{DNA constructs}

pha-4::GFP carries GFP from pPD95.85 (http://www.ciwemb.edu; Fire et al. 1990) inserted into a unique MluI site at position 5612 relative to ATG1 of pha-4. The genomic pha-4 sequences extend from -7110 to +7683 . GPtxg carries the pan-pharyngeal promoter region from -589 to -1 of T05E11.3 (Gaudet and Mango 2002) fused to GFP from pAP10 (A. Paulson and S.E. Mango, unpubl.; G. Seydoux, pers. comm.). The 3' end of GFP is fused in-frame to pha- 4 cDNA from +4 to +507 relative to the first ATG. $p G F P$ is described in Portereiko and Mango (2001) and tlf-1::GFP in Kaltenbach et al. (2000). pha-4::GFP, tlf-1::GFP, and $p G F P$ are simple arrays integrated into the genome. GPtxg is a complex extrachromosomal array. GFPhp is derived from L4271 (http:// www.ciwemb.edu; 1999 Fire vector kit; Winston et al. 2002) with the lacZ promoter inactivated.

\section{Site-directed mutagensis}

We inactivated the lacZ promoter from L4271 and pBluescript KSby replacing six bases at the $-10 \mathrm{LacZ}$ with a $S c a-1$ restriction site. Primers were designed for the pBlusecript backbone (For lacZ sca-1, CACTTTATGCTTCCGGCTCGAGTACTTGTGGAATTGT GAGCGG; rev lacZ sca-1, CCGCTCACAATTCCACAAGTACTC GAGCCGGAAGCATAAAGTG) and amplified using PfuTURBO and digested with $D p n I$ prior to transformation (QuickChange Site-Directed Mutagenesis Kit, Stratagene). Hairpins constructed in pCRII2.1 TOPO were inserted into pBluescript KS- by sequentially digesting with $K p n I$ and NotI and ligating with T4 DNA ligase following standard procedures.

\section{dsRNA production}

Amplicons were transcribed using T7 or SP6 transcription kits (Ambion Megascript). All clonedfragments were linearized prior to transcription. GFP: The full-length (1-715 bp), 5' (1-357 bp), middle (181-535 bp), and 3' (358-715 bp) GFP sequences were amplified from GFP::unc-22::PFG plasmid L4271 (http://www. ciwemb.edu; Fire et al. 1990). unc-60A and unc-60B: Primers containing T7 and SP6 promoters were designed to unc-60A (1-498 bp) and unc-60B (499-882 bp). Amplicons of the desired size were obtained from the Okkema embryonic cDNA library, gel purified, and transcribed. Most forward and reverse primers were designed with T7 or SP6 promoter sites for in vitro transcription. Primers with no promoter sites were cloned into pCRII TOPO (Invitrogen).

\section{ACKNOWLEDGMENTS}

We thank Drs. Ono and Seydoux for reagents; L. Kaltenbach for helpful suggestions; B. Cairns, C. Kaplan, and S. Knight for comments on the manuscript; and W. Winston and C. Hunter for discussions about hairpin dsRNA RNAi. We thank Mike Horner and Maggie Woolf for expert technical assistence. This work was supported by the Huntsman Cancer Institute Center for Children and Cancer Center Support Grant 2P30CA42014.

The publication costs of this article were defrayed in part by payment of page charges. This article must therefore be hereby marked "advertisement" in accordance with 18 USC section 1734 solely to indicate this fact.

Received May 20 2002; accepted September 262002.

\section{REFERENCES}

Bernstein, E., Caudy, A.A., Hammond, S.M., and Hannon, G.J. 2001a. Role for a bidentate ribonuclease in the initiation step of RNA interference. Nature 409: 363-366.

Bernstein, E., Denli, A.M., and Hannon, G.J. 2001b. The rest is silence. RNA 7: 1509-1521.

Boutla, A., Kalantidis, K., Tavernarakis, N., Tsagris, M., and Tabler, M. 2002. Induction of RNA interference in Caenorhabditis elegans by RNAs derived from plants exhibiting post-transcriptional gene silencing. Nucleic Acids Res. 30: 1688-1694.

Brenner, S. 1974. The genetics of Caenorhabditis elegans. Genetics 77: 71-94.

Catalanotto, C., Azzalin, G., Macino, G., and Cogoni, C. 2002. Involvement of small RNAs and role of the qde genes in the gene silencing pathway in Neurospora. Genes \& Dev. 16: 790-795.

Celotto, A.M. and Graveley, B.R. 2002. Exon-specific RNAi: A tool for dissecting the functional relevance of alternative splicing. RNA 8: 718-724.

Cogoni, C. and Macino, G. 1999a. Gene silencing in Neurospora crassa requires a protein homologous to RNA-dependent RNA polymerase. Nature 399: 166-169.

. 1999b. Posttranscriptional gene silencing in Neurospora by a RecQ DNA helicase. Science 286: 2342-2344.

Dalmay, T., Hamilton, A., Rudd, S., Angell, S., and Baulcombe, D.C. 2000. An RNA-dependent RNA polymerase gene in Arabidopsis is required for posttranscriptional gene silencing mediated by a transgene but not by a virus. Cell 101: 543-553.

Dalmay, T., Horsefield, R., Braunstein, T.H., and Baulcombe, D.C. 2001. SDE3 encodes an RNA helicase required for post-transcriptional gene silencing in Arabidopsis. EMBO J. 20: 2069-2078.

Domeier, M.E., Morse, D.P., Knight, S.W., Portereiko, M., Bass, B.L., and Mango, S.E. 2000. A link between RNA interference and nonsense-mediated decay in Caenorhabditis elegans. Science 289: 19281931.

Elbashir, S.M., Lendeckel, W., and Tuschl, T. 2001a. RNA interference is mediated by 21- and 22-nucleotide RNAs. Genes \& Dev. 15: 188-200.

Elbashir, S.M., Martinez, J., Patkaniowska, A., Lendeckel, W., and Tuschl, T. 2001b. Functional anatomy of siRNAs for mediating efficient RNAi in Drosophila melanogaster embryo lysate. EMBO J. 20: $6877-6888$.

Fagard, M., Boutet, S., Morel, J.B., Bellini, C., and Vaucheret, H. 2000. AGO1, QDE-2, and RDE-1 are related proteins required for posttranscriptional gene silencing in plants, quelling in fungi, and RNA interference in animals. Proc. Natl. Acad. Sci. 97: 11650-11654.

Fire, A., Harrison, S.W., and Dixon, D. 1990. A modular set of lac-Z fusion vectors for studying gene expression in C. elegans. Gene 93: 189-198.

Fire, A., Xu, S., Montgomery, M.K., Kostas, S.A., Driver, S.E., and Mello, C.C. 1998. Potent and specific genetic interference by double-stranded RNA in Caenorhabditis elegans. Nature 391: 806811.

Gaudet, J. and Mango, S.E. 2002. Regulation of organogenesis by the Caenorhabditis elegans FoxA protein PHA-4. Science 295: 821-825.

Grishok, A., Tabara, H., and Mello, C.C. 2000. Genetic requirements for inheritance of RNAi in C. elegans. Science 287: 2494 2497.

Grishok, A., Pasquinelli, A.E., Conte, D., Li, N., Parrish, S., Ha, I., Baillie, D.L., Fire, A., Ruvkun G., and Mello, C.C. 2001. Genes and mechanisms related to RNA interference regulate expression of the small temporal RNAs that control C. elegans developmental timing. Cell 106: 23-34.

Hammond, S.M., Boettcher, S., Caudy, A.A., Kobayashi, R., and Han- 
non, G.J. 2001. Argonaute2, a link between genetic and biochemical analyses of RNAi. Science 293: 1146-1150.

Holen, T., Amarzguioui, M., Wiiger, M.T., Babaie, E., and Prydz, H. 2002. Positional effects of short interfering RNAs targeting the human coagulation trigger Tissue Factor. Nucleic Acids Res. 30: $1757-1766$.

Hutvagner, G. and Zamore, P.D. 2002. A microRNA in a multipleturnover RNAi enzyme eomplex. Science (in press).

Kaltenbach, L., Horner, M.A., Rothman, J.H., and Mango, S.E. 2000. The TBP-like factor CeTLF is required to activate RNA polymerase II transcription during C. elegans embryogenesis. Mol. Cell 6: 705713.

Ketting, R.F., Haverkamp, T.H., van Luenen, H.G., and Plasterk, R.H. 1999. mut-7 of C. elegans, required for transposon silencing and RNA interference, is a homolog of Werner syndrome helicase and RNaseD. Cell 99: 133-141.

Ketting, R.F., Fischer, S.E., Bernstein, E., Sijen, T., Hannon, G.J., and Plasterk, R.H. 2001. Dicer functions in RNA interference and in synthesis of small RNA involved in developmental timing in $C$. elegans. Genes \& Dev. 15: 2654-2659.

Knight, S.W. and Bass, B.L. 2001. A role for the RNase III enzyme DCR-1 in RNA interference and germ line development in $C$. elegans. Science 293: 2269-2271.

Labouesse, M. and Mango, S.E. 1999. Patterning the C. elegans embryo: Moving beyond the cell lineage. Trends Genet. 15: 307-313.

Lipardi, C., Wei, Q., and Paterson, B.M. 2001. RNAi as random degradative PCR: siRNA primers convert mRNA into dsRNAs that are degraded to generate new siRNAs. Cell 107: 297-307.

Mango, S.E. 2001. Stop making nonSense: The C. elegans smg genes. Trends Genet. 17: 646-653.

Mango, S.E., Lambie, E.J., and Kimble, J. 1994. The pha-4 gene is required to generate the pharyngeal primordium of Caenorhabditis elegans. Development 120: 3019-3031.

Martens, H., Novotny, J., Oberstrass, J., Steck, T.L., Postlethwait, P., and Nellen, W. 2002. RNAi in Dictyostelium: The role of RNAdirected RNA polymerases and double-stranded RNase. Mol. Biol. Cell 13: 445-453.

McKim, K.S., Matheson, C., Marra, M.A., Wakarchuk, M.F., and Baillie, D.L. 1994. The Caenorhabditis elegans unc-60 gene encodes proteins homologous to a family of actin-binding proteins. Mol. Gen. Genet. 242: 346-357.

Moerman, DG. and Fire, A. 1997. Muscle: Structure, function and development. In C. elegans II (eds. D.L. Riddle et al.), pp. 417-470. Cold Spring Harbor Laboratory Press, Cold Spring Harbor, NY.

Mourelatos, Z., Dostie, J., Paushkin, S., Sharma, A., Charroux, B., Abel, L., Rappsilber, J., Mann, M., and Dreyfuss, G. 2002. miRNPs: A novel class of ribonucleoproteins containing numerous microRNAs. Genes \& Dev. 16: 720-728.

Mourrain, P., Beclin, C., Elmayan, T., Feuerbach, F., Godon, C., Morel, J.B., Jouette, D., Lacombe, A.M., Nikic, S., Picault, N., et al. 2000. Arabidopsis SGS2 and SGS3 genes are required for posttranscriptional gene silencing and natural virus resistance. Cell 101: 533-542.

Nykanen, A., Haley, B., and Zamore, P.D. 2001. ATP requirements and small interfering RNA structure in the RNA interference pathway. Cell 107: 309-321.

Parrish, S. and Fire, A. 2001. Distinct roles for RDE-1 and RDE-4 during RNA interference in Caenorhabditis elegans. RNA 7: 13971402.

Parrish, S., Fleenor, J., Xu, S., Mello, C., and Fire, A. 2000. Functional anatomy of a dsRNA trigger. Differential requirement for the two trigger strands in RNA interference. Mol. Cell 6: 1077-1087.

Plasterk, R.H.A. and van Luenen, H.G.A.M. 1997. Transposons. In C. elegans II (eds. D.L. Riddle et al.), pp. 97-116. Cold Spring Harbor Laboratory Press, Cold Spring Harbor, NY.

Portereiko, M.F. and Mango, S.E. 2001. Early morphogenesis of the Caenorhabditis elegans pharynx. Dev. Biol. 233: 482-494.

Schiebel, W., Haas, B., Marinkovic, S., Klanner, A., and Sanger, H.L. 1993a. RNA-directed RNA polymerase from tomato leaves. I. Purification and physical properties. J. Biol. Chem. 268: 11851-11857. . 1993b. RNA-directed RNA polymerase from tomato leaves. II. Catalytic in vitro properties. J. Biol. Chem. 268: 11858-11867.

Schiebel, W., Pelissier, T., Riedel, L., Thalmeir, S., Schiebel, R., Kempe, D., Lottspeich, F., Sanger, H.L., and Wassenegger, M. 1998. Isolation of an RNA-directed RNA polymerase-specific cDNA clone from tomato. Plant Cell 10: 2087-2101.

Sharp, P.A. 2001. RNA interference - 2001. Genes \& Dev. 15: 485-490.

Sijen, T., Fleenor, J., Simmer, F., Thijssen, K.L., Parrish, S., Timmons, L., Plasterk, R.H., and Fire, A. 2001. On the role of RNA amplification in dsRNA-triggered gene silencing. Cell 107: 465-476.

Smardon, A., Spoerke, J.M., Stacey, S.C., Klein, M.E., Mackin, N., and Maine, E.M. 2000. EGO-1 is related to RNA-directed RNA polymerase and function in germ-line development and RNA interference in C. elegans. Curr. Biol. 10: 169-178.

Tabara, H., Sarkissian, M., Kelly, W.G., Fleenor, J., Grishok, A., Timmons, L., Fire, A., and Mello, C.C. 1999. The $r d e-1$ gene, RNA interference, and transposon silencing in C. elegans. Cell 99: 123132.

Tabara, H., Yigit, E., Siomi, H., and Mello, C.C. 2002. The dsRNA binding protein RDE-4 interacts with RDE-1, DCR-1, and a DExH-box helicase to direct RNAi in C. elegans. Cell 109: 861-871.

Tijsterman, M., Ketting, R.F., Okihara, K.L., Sijen, T., and Plasterk, R.H. 2002. RNA helicase MUT-14-dependent gene silencing triggered in C. elegans by short antisense RNAs. Science 295: 694-697.

Timmons, L. and Fire, A. 1998. Specific interference by ingested dsRNA. Nature 395: 854.

Timmons, L., Court, D.L., and Fire, A. 2001. Ingestion of bacterially expressed dsRNAs can produce specific and potent genetic interference in Caenorhabditis elegans. Gene 263: 103-112.

Vaistij, F.E., Jones, L., and Baulcombe, D.C. 2002. Spreading of RNA targeting and DNA methylation in RNA silencing requires transcription of the target gene and a putative RNA-dependent RNA polymerase. Plant Cell 14: 857-867.

Winston W.M., Molodowitch, C., and Hunter, C.P. Systemic RNAi in C. elegans requires the putative transmembrane protein SID-1. Science 295: 2456-2459.

Wu-Scharf, D., Jeong, B., Zhang, C., and Cerutti, H. 2000. Transgene and transposon silencing in chlamydomonas reinhardtii by a DEAH-Box RNA helicase. Science 290: 1159-1163.

Zamore, P.D. 2001. RNA interference: Listening to the sound of silence. Nat. Struct. Biol. 8: 746-750.

Zamore, P.D., Tuschl, T., Sharp, P.A., and Bartel, D.P. 2000. RNAi: Double-stranded RNA directs the ATP-dependent cleavage of mRNA at 21 to 23 nucleotide intervals. Cell 101: 25-33. 

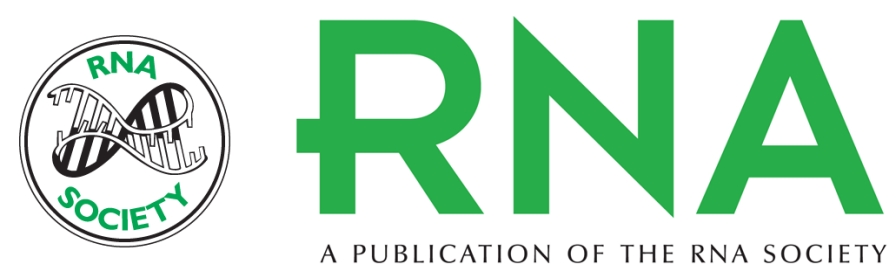

A PUBLICATION OF THE RNA SOCIETY

\section{Gene silencing in Caenorhabditis elegans by transitive RNA interference}

MATTHEW N. ALDER, SHALE DAMES, JEFFREY GAUDET, et al.

RNA 2003 9: 25-32 $\begin{array}{ll}\text { References } & \begin{array}{l}\text { This article cites } 52 \text { articles, } 26 \text { of which can be accessed free at: } \\ \text { http://rnajournal.cshlp.org/content/9/1/25.full.html\#ref-list-1 }\end{array}\end{array}$

\section{License}

Email Alerting Receive free email alerts when new articles cite this article - sign up in the box at the Service top right corner of the article or click here.

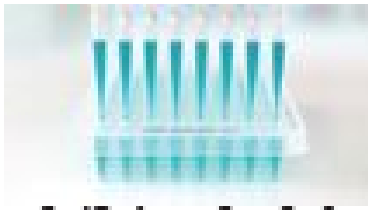

